\section{PLANTS OF DOWNS AND DUNES}

\section{Downs and Dunes}

Their Plant Life and its Environment. By Sir Edyard Salisbury. Pp. xiii $+328+32$ plates. (London : G. Bell and Sons, Ltd., 1952.) 45s. net.

7 HIS book had its immediate origin in the lectures delivered by the author as the Fullerton professor at the Royal Institution, but it arises ultimately from the life-long experience of Sir Edward Salisbury as a field naturalist and his deep interest in living plants, whether in field or garden. Indeed, one of the great merits of the book lies in the wealth of original observations which it contains. This should be pointed out, since it may not be easily appreciated by the non-specialist reader that he is presented here with what is to a great extent an original work, containing the fruit of extensive first-hand observation in the field. Botanists who are ecologically minded (and who in these days is not ?) will be grateful for the material the author has provided for them. Sir Edward has always had the knack of publishing some of his most valuable research through unusual channels, and instead of spreading his information through a number of orthodox papers, as many others would have done, he has chosen to put it together in the form of a semi-popular book. If this leads the professed ecologist to overlook the book, it will be a pity, since he will find in it a great deal of material of the highest value to him. On the other hand, it will reach a larger public, and may open the eyes of interested country-lovers to the importance of detailed observation of the actual conditions of life among wild plants, and encourage them to undertake a wider kind of field-work than the 'naming' of plants, much of which can be carried out by any intelligent person, in which case the gain may be considerable.

The book refers, of course, to Britain, and the general outlook is, as we have noticed, ecological rather than systematic or geographical. In some respects it invites comparison with the recent publication by Lousley of "Flowers of the Chalk and Limestone"; but the bias of the two books is quite different, as the latter is mainly preoccupied with questions of floristics and distribution.

The association of downs and dunes together may strike the reader as an odd combination, and indeed, in spite of what the author claims in his preface, it is difficult to avoid the feeling that the link is primarily subjective. The two types of habitat share the qualities of having relatively dry, open, well-drained soils and, in part, the calcareous character; but the contrasts, both ecologically and floristically, are more impressive than the resemblances.

There is a substantial discussion of characteristic species, treating the plants of chalk grassland, calcareous beechwood, chalk scrub, chalk arable, limestone, yellow dunes, grey dunes and dune slacks as separate assemblages; but these chapters are called "Biological Notes", and they deal, not with taxonomic characters, which is the business of a Flora, but with the life-histories and environmental relationships of each species, information about which is often difficult to obtain and requires firsthand observation in the field. This was to be expected from one of the projectors of the "Biological Flora", which is slowly building up, species by species, in the hands of specialists, a body of the sort of information this book sets out to give in its more limited field.

Criticism of such a book as this is apt to take an individual form, since no two people would plan the work in the same way. Here and there, too, one may differ, though tentatively where so much is uncertain, from an opinion expressed. Viewed from a larger aspect, one regrets that no mention is made of chalk heath, that remarkable and fastdisappearing form of vegetation. The scrub lands of chalk and dunes are rather scantily treated, and more would have been acceptable on the beech itself. It has been expertly dealt with elsewhere, but in publications not so likely to be available to the general reader.

There is a most interesting and all too short chapter on gardening on calcareous soils, and one could have wished for similar enlightenment on seaside gardening.

The illustrations, drawings and photographs are excellent and nearly all are original. The photographs are admirably reproduced, and the type and format are very pleasant. The reviewer was delighted to see an acknowledgment to the late Prof. F. W. Oliver, to whose wisdom and deep knowledge of plants he, in common with the author, owes so much.

R. C. McLean

\section{CHEMISTRY AND AGRICULTURE}

\section{Agricultural Chemistry}

A Reference Text. By Prof. Donald E. H. Frear. Vol. 1 : Principles of Agricultural Chemistry ; pp. viii +812; $(1950) ; 66 s$. net. Vol. 2: Practical Applications of Agricultural Chemistry ; pp. viii + 588 ; (1951) ; 71s. net. (New York : D. Van Nostrand Co., Inc. ; London : Macmillan and Co., Ltd.)

VEAR-TO-YEAR fluctuations in regional harvests, dependent on chance climatic and other environmental conditions, cannot hide the fact that the general trend, in the more densely populated areas of the world, is for supplies of foods for human consumption to become less and less adequate to meet the needs of an ever-increasing population. It needs no seer to predict that, ruling out miracles, unless there occurs either the highly unlikely eventuality of a rapid and widespread reduction in birth-rate, or a great intensification of the application of modern agricultural science and technique to the world's cultivable acreage, a steady fall in the already meagre nutritional standards of perhaps two-thirds of the world's population, with increasing individual misery and growing social repercussions, is inevitable. Further, standards of living other than the nutritional are scarcely less related fundamentally to supplies of raw material of agricultural or forest origin. As the world's diminishing reserves of coal and oil approach exhaustion, supplies of raw materials for the manufacture of many industrial carbon compounds will have to be found elsewhere, and the strain on the areas used for food crops cannot fail to be further increased.

The many-sided applications of chemistry to the improvement of yield and quality of cultivated crops, if put into practice in time on a large enough scale 